Flow in Channels 
Macmillan Engineering Hydraulics Series 


\title{
Flow in Channels
}

\author{
Robert H. J. Sellin, B.Sc., Ph.D.
}

Lecturer in hydraulics, Department of Civil Engineering, The Queen's University of Belfast, Northern Ireland.

\section{Macmillan}

St. Martin's Press 
ISBN 978-1-349-00197-2

ISBN 978-1-349-00195-8 (eBook)

DOI 10.1007/978-1-349-00195-8

(C) R. H. J. Sellin 1969.

Softcover reprint of the hardcover 1st edition 1969 978-0-333-02822-3

First Published in 1969.

Published by MACMILLAN AND CO LTD Little Essex Street London wc2 and also at Bombay Calcutta and Madras Macmillan South Africa (Publishers) Pty Ltd Johannesburg The Macmillan Company of Australia Pty Ltd Melbourne The Macmillan Company of Canada Ltd Toronto St Martin's Inc New York 


\section{Preface}

This book is intended mainly for students of hydraulic engineering who have already gained a basic knowledge of fluid mechanics and who wish to study the hydraulics of open channels as a whole. At the same time it is hoped that the inclusion of a full range of selected references will make the book of value to postgraduate students and practising engineers looking for an introduction to the subject.

Although flow in channels constitutes only one part of hydraulics, it is today too large a subject for it to be treated easily in detail in a single small volume. Here, an introduction to alluvial or loose boundary flow as well as one to unsteady channel flow is given, together with the more complete treatment of uniform and nonuniform flow in fixed boundary channels.

A student using the early chapters of this book will be expected to be familiar with the application to fluid mechanics of such basic concepts as energy, momentum and continuity as well as with the simple properties of fluids. An understanding of the boundary layer concept and the existence of shear stresses in fluids will also be an advantage. The references given at the end of each chapter have been selected on two criteria: they either describe important original work or thinking on the topic under discussion or else they refer to more complete treatments of the subject than is possible in the present volume. It was the author's intention to make the second category as up to date as possible bearing in mind that the best in 
hydraulics appears to have an enduring validity that far exceeds many other disciplines in science and technology.

In conclusion, it is necessary for me to express my indebtedness to all those from whom I have learnt both personally and through print. The foundations of the subject were most carefully laid by Dr. E. F. Gibbs of the University of Bristol without whose interest and encouragement I might never have pursued the subject further. Finally I would like to thank Professor T. M. Charlton for the opportunity to write this book and his continuing interest in it.

Department of Civil Engineering,

The Queen's University of Belfast

R. H. J. Sellin 


\section{Contents}

Preface

1 Uniform flow 1

1.1 General characteristics of open channel flow

1.2 Definition and occurrence of uniform channel flow

1.3 Empirical formulae

1.4 Normal depth of a stream

1.5 Velocity distribution in a cross-section

1.6 Fundamental flow relationships

1.7 Hydraulic efficiency of cross-section

1.8 Free surface flow in closed conduits

1.9 Ice covered streams

2 Gradually varied flow

2.1 Total energy and specific energy

2.2 Critical depth and critical velocity

2.3 General equation of gradually-varied flow 
2.4 Varied flow surface profiles

2.5 Solution of gradually varied flow equation

3 Rapidly varied flow

3.1 Control sections

3.2 Transition through critical depth

3.3 Analysis of the hydraulic jump

3.4 Flow through a sluice-horizontal force on the structure

3.5 Flow past a submerged obstacle

3.6 Changes in channel width

4 Control and measurement of open channel flow

4.1 River utilisation

4.2 Channel regulation

4.3 Flow measurement

5 Flow in erodible material

5.1 Introduction

5.2 Sources and types of sediment

5.3 Modes of sediment transport

5.4 Different approaches to the problem of sediment transport

5.5 Sediment movement as bed load

5.6 Suspended sediment movement

5.7 Total sediment load

5.8 Regime behaviour of channels

5.9 River bends and meandering

5.10 Formation of alluvial plains

5.11 The design of stable canals

5.12 Sedimentation in reservoirs 
6 Unsteady flow in open channels

6.1 Outline and classification

6.2 Hydrographs and flood waves

6.3 Flood routing through open channels

6.4 Flood routing through reservoirs

References

List of Notations

142

Index 